\title{
Quantitative analysis on coupling of traction current into cab signaling in electrified railways
}

\author{
Chang Liu ${ }^{1} \cdot$ Shiwu $\operatorname{Yang}^{1}\left[\right.$ [D $\cdot$ Yong $\mathrm{Cui}^{1} \cdot \mathrm{Jiaqi}^{\mathrm{Lv}^{2}}$
}

Received: 6 July 2020/Revised: 20 August 2020/ Accepted: 25 August 2020/Published online: 19 September 2020

(C) The Author(s) 2020

\begin{abstract}
Cab signaling apparatus is the critical equipment for ground-vehicle communication in electrified railways. With the rapid development of high-speed and heavy-haul railways, the immunity to unbalanced traction current interference for cab signaling apparatus in the onboard train control system is increasingly demanded. This paper analyzes the interference coupling mechanism of the ZPW2000 track circuit. Based on electromagnetic field theory and the actual working parameters, a calculation model is established to complete the quantitative research of the cab signal induction process and traction current interference. Then, a finite element model is built to simulate the process. The simulation results under the signal frequency, fundamental and harmonic interference are all consistent with the theoretical calculation results. The practical measurement data verify the coupling relationship between cab signal inductive voltage and rail current. Finally, an indirect immunity test method applying this relation for the cab signals is proposed, and the voltage indexes of the disturbance sources are determined, i.e., the test limits. The results provide an accurate quantitative basis for the cab signaling research and design of the immunity test platform; besides, the proposed indirect test method can simplify the test configuration and improve test efficiency.
\end{abstract}

Shiwu Yang

ysw@bjtu.edu.cn

Chang Liu

19111061@bjtu.edu.cn

1 School of Electronic and Information Engineering, Beijing Jiaotong University, Beijing 100044, China

2 Research and Development Center, CRSC Urban Rail Transit Technology Co., Ltd, Beijing 100166, China
Keywords Cab signaling · Electromagnetic field · Track circuit - Immunity test - Traction current interference

\section{Introduction}

The cab signaling apparatus, also known as the specific transmission module (STM) or the track circuit reader (TCR), is a kind of crucial information receiving equipment in the Chinese train control system (CTCS) or European train control system (ETCS) onboard subsystem. It cooperates with the ground track circuit to complete the transmission of the train control information from the ground to the train through the electromagnetic induction process. The information is then demodulated, decoded, and transmitted to the vital computer for processing, to achieve train control, or to provide visualized control information through the driver machine interface (DMI). Therefore, it is designed to meet the high-safety and highreliability requirements of onboard equipment under highspeed rail conditions and plays an essential role in the vehicle-to-ground wireless communication. With the development of high-speed and heavy-haul railways, the traction power has increased remarkably, and the types of electric locomotives are diversified, which makes the electromagnetic environment more complicated. For rolling stock, the problem of electromagnetic compatibility (EMC) between the high current in the traction power supply system and the weak current transmitted by the railway signaling is becoming increasingly prominent. Since the induction of the cab signal is realized by the receiving antenna outside the locomotive, it is susceptible 
to electromagnetic interference in the surrounding space, and the unbalanced traction current interference in the rails is particularly serious. According to the statistic of railway operation, unbalanced currents have continuously interfered with cab signals to cause potential equipment failure, which directly affects the railway operation efficiency and jeopardizes operation safety.

EN 50238-2 defined the interference current emission limits of rolling stock but did not mention its interference voltage immunity limits after coupling the interference current [1]. Given the importance of cab signals to electrified interference protection, relevant railway standards proposed some immunity requirements [2, 3]. However, concerning the actual cab signaling immunity test and research \& development process, there are still a few intensive problems such as insufficient signal current data, the incomplete corresponding relationship between interference current and inductive voltage, and defective test configuration regulations. At present, the quantitative research on the anti-interference technique and immunity test of cab signaling is relatively a blank field. In terms of cab signal inductive mechanism and related topics, Augutis et al. [4] created a system to record cab signaling system signals and proposed a method to process the signals. Chen et al. [5] proposed a virtual instrument-based loop inspecting method of cab signal. Zhao et al. [6] verified the linear relationship in amplitude between the rail current and the antenna voltage based on the actual data of the railway site, but the quantitative representation of this relationship is still lacking. Obviously, the in-depth numerical analysis of the coupling mechanism of the cab signal has become the primary problem that should be solved in its anti-interference research and the immunity test. The interference source we are concerned about generally refers to the traction current coupled from the rails to the locomotive. In terms of the research on traction current interference, Zhang et al. [7] established the calculation model of the magnetic interference to signal cable based on the multi-conductor transmission line theory. Charalambous et al. [8] holistically assessed the electromagnetic interference (EMI) on underground pipelines near alternating current (AC) traction systems. Serdiuk et al. [9] analyzed the EMC of track circuits with the traction supply system of the railway through mathematical modeling. Liu et al. [10] proposed a voltage-balancing solution of the single-phase AC/AC modular multilevel converter to avoid interferences with input/output voltage and current. Havryliuk [11] modeled and analyzed the return traction current harmonics distribution in rails for AC electric railway system. Blahnik et al. [12] analyzed low harmonic interferences of AC-direct current (DC) traction converter and the influence of selected signals. Furthermore, in the research on cab signaling anti-interference, Augutis et al.
[13] analyzed the influence of disturbing signals caused by rail magnetization to a cab signaling system. Wu et al. [14] proposed the content and related requirements of the antielectrical interference test of the railway signaling apparatus. Chen et al. [15] considered the problem that the cab signals were interfered with by the adjacent rails and proposed a method to increase its immunity by adding a shield. In summary, the research on the coupling mechanism of this area is still based on field tests and relatively intuitive simplified modeling, while lacking complete and detailed mathematical models. For the cab signaling immunity test, the existing related research pays more attention to the reliability of the indoor test and improves the automation of the test, but the normalized quantitative basis and simulation analysis are in urgent need.

This paper takes China's mainstream ZPW-2000 track circuit as the ground signal source. We consider the cab signaling host as the equipment under test (EUT) and analyze the railway's actual electromagnetic environment. The focus is based on the electromagnetic theory to complete the qualitative analysis of the traction current interference coupling mechanism and the quantitative calculation of host input voltage, which is preliminarily proven using the finite element simulation model. Furthermore, the above theoretical calculation results are verified by the immunity test and applied as voltage indexes to propose an indirect test method without current conduction through the rails. The method can not only simplify the test circuit, improve the test efficiency, but also effectively avoid the test error caused by coupling other electromagnetic field energy in the current transmission path, thereby ensuring the test accuracy.

\section{Analysis and theoretical calculation of magnetic coupling process}

\subsection{Analysis of the interference mechanism}

The cab signaling sensor apparatus, i.e., the cab signaling dual receiving antennas, are installed directly behind the locomotive bogie above the rails, and one on each side. The distance between the bottom surface of the antenna and the rail surface is $155 \mathrm{~mm} \pm 5 \mathrm{~mm}$. The error between the longitudinal center of the antenna and the longitudinal center of the rail is less than $5 \mathrm{~mm}$, while the horizontal spacing between the transverse center of the antenna and the pair of shunting wheels is $1500 \mathrm{~mm}$. In order to achieve reliable acquisition of the differential-mode current signal in the rails, the antenna coils circuit was designed as a dualchannel redundancy design. It is embodied by the fact that a total of four sets of coils on the two receiving antennas adopt a twin channel series-opposing connection of their 
dotted terminals. Assuming that the coils on antennas 1 and 2 are L12A, L12B, L34A, and L34B in sequence. Take L12A and L34A as one group, and take L12B and L34B as another group, which are, respectively, used as two input ends of the EUT and equivalent in normal operation [16].

The signal current in the rail (ground track circuit current) is the main excitation source during the normal operation of the cab signal transmission. The input voltage of the EUT and the rail current all belong to the frequency shift keying (FSK) signal, expressed as follows:

$\gamma(t)=A_{\mathrm{f}} \cos \left(2 \pi f_{\mathrm{c}} t \pm 2 \pi \Delta f_{\mathrm{p}} \int s_{\mathrm{m}}(t) \mathrm{d} t+\varphi_{0}\right)$,

where $\gamma(t)$ is the current or voltage signal transmitted by the track circuit or cab signaling apparatus, $A_{\mathrm{f}}$ is the amplitude of the current or voltage signal, $f_{\mathrm{c}}$ is the carrier frequency, $\Delta f_{\mathrm{p}}$ is the frequency offset, $\varphi_{0}$ is the initial phase, and $s_{\mathrm{m}}(t)$ is the modulating signal. Its time domain is characterized by a square wave with a duty ratio of $1: 1$ and the modulated frequency $\left(f_{\mathrm{d}}\right)$, containing the speed information for both the track circuit and the cab signaling.

The traction current is supplied by the pantograph over the locomotive and flows into the rails through the wheels from the locomotive transformer and the locomotive load [17]. Due to the imbalance of the following factors: impedance of the two rails, the ground equipment and their earth impedance, the contact impedance between the discharge wheels and the rails, etc., the overall impedance of the two traction current loops are not equal, finally leading to the traction current distributed in the two rails unequal; i.e., the unbalanced traction current is formed [18, 19]. While the locomotive is swaying and vibrating during the running process, the contact resistances between the two discharge wheels and the rails are usually different slightly. The unbalanced traction current in two rails causes the common-mode transmission to be converted into differential-mode interference, which in turn interferes with the cab signal, as shown in Fig. 1.

In Fig. $1, i_{\mathrm{FSK}}$ is the signal current, $i_{1}$ and $i_{2}$ are the respective total currents of the two rails, while $i_{\mathrm{t} 1}$ and $i_{\mathrm{t} 2}$ are the respective traction currents; ideally, $i_{\mathrm{t} 1}=i_{\mathrm{t} 2}$, $i_{1}=i_{\mathrm{t} 1}+i_{\mathrm{FSK}}$, and $i_{2}=i_{\mathrm{t} 2}-i_{\mathrm{FSK}}$. In the case of imbalance, $i_{\mathrm{t} 1}$ and $i_{\mathrm{t} 2}$ can be decomposed into differential-mode current $i_{\mathrm{d}}$ (equal in two rails, with opposite directions) and common-mode current $i_{\mathrm{c}}, \quad$ i.e., $\quad i_{\mathrm{t} 1}=i_{\mathrm{c}}+i_{\mathrm{d}} \quad$ and $i_{\mathrm{t} 2}=i_{\mathrm{c}}-i_{\mathrm{d}}$, causing the unbalanced traction current of $2 i_{\mathrm{d}}$ between two rails. As a result, the differential-mode current $i_{\mathrm{d}}$ is coupled to the EUT along with the signal current $i_{\mathrm{FSK}}$. However, the electric locomotive is a large-capacity, single-phase, and nonlinear load with severe fluctuations [20]. Due to the distortion, the traction current contains not only $50 \mathrm{~Hz}$ sinusoidal fundamental wave, but also rich harmonic components even extending to signal frequency range [21].
As a result, it may interfere with the decoding of the cab signal.

\subsection{Modeling and calculation of the electromagnetic environment}

The values in the electromagnetic induction process of the cab signaling apparatus can be calculated based on Maxwell's equations [22] and Biot-Savart law [23]. We establish a rectangular coordinate system of the EUT, as shown in Fig. 2 (single side rail), where each parameter is in millimeters $(\mathrm{mm})$.

In Fig. 2, the coordinate origin is $O$, and the directions of the vectors $\overrightarrow{b a}, \overrightarrow{g a}$, and $\overrightarrow{b c}$ on the antenna core are the positive directions of the $x$-axis, the $y$-axis, and the $z$-axis, respectively. The track gauge is $d=1435 \mathrm{~mm}$, the length of the rail is $l=2000 \mathrm{~mm}$, and the horizontal distance between the simulated shunting wheelset and the antenna center is $k=1500 \mathrm{~mm}$. In this practical engineering problem, only the low-frequency magnetic field with a small intensity is involved, and only the rails within a length of 0 to $l$ are considered. Take the rail model P60, its height $H=176 \mathrm{~mm}$, and the distance between the bottom of the magnetic core and the bottom of the antenna case is $23.6 \mathrm{~mm}$. Therefore, the distance between the rail surface and the rail center (or the half-height of the rail) is 176/ $2=88 \mathrm{~mm}$, and the vertical distance between the bottom of the magnetic core and the rail center is $h=155 \mathrm{~mm}+23.6 \mathrm{~mm}+88 \mathrm{~mm}=266.6 \mathrm{~mm}$. The length of the iron core along the $y$-axis direction is $2 l_{\mathrm{p}}$, and the length in directions $x$-axis and $z$-axis are both $2 l_{\mathrm{q}}$. The distance between the two coils on the iron core is $2 l_{\mathrm{z}}$. The length and turn number of a single set of coils are $l_{\mathrm{x}}$ and $q_{\mathrm{m}}=12$, respectively. The actual measurement shows that the radius of a single set of coils is $r \approx 1.35 \mathrm{~mm}$. Other relevant layout conditions conform to the actual installation conditions of the receiving antenna.

The magnetic flux distribution of the antenna receiver coils is analyzed with reference to Fig. 2, as shown in Fig. 3a.

The four sets of coils magnetic fluxes are denoted as $\phi_{n}$ $(n=1,2,3,4)$, where $\phi_{n 1}(n=1,2,3,4)$ represents the selfmagnetic flux of each set of coils from rail $1, \phi_{n 2}$ $(n=1,2,3,4)$ represents the self-magnetic flux of each set of coils from rail 2 , and $\phi_{n \mathrm{~m}}(n=1,2,3,4)$ represents the mutual flux that the coils receive on the same core. Then we can derive

$\left\{\begin{array}{l}\phi_{1}(t)=\phi_{11}(t)+\phi_{12}(t)+\phi_{1 \mathrm{~m}}(t) \\ \phi_{2}(t)=\phi_{21}(t)+\phi_{22}(t)+\phi_{2 \mathrm{~m}}(t) \\ \phi_{3}(t)=\phi_{31}(t)+\phi_{32}(t)+\phi_{3 \mathrm{~m}}(t) \\ \phi_{4}(t)=\phi_{41}(t)+\phi_{42}(t)+\phi_{4 \mathrm{~m}}(t)\end{array}\right.$. 


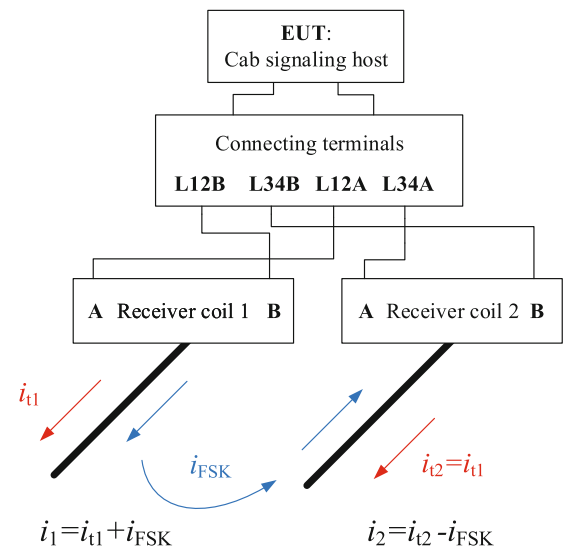

(a) When traction current is balanced

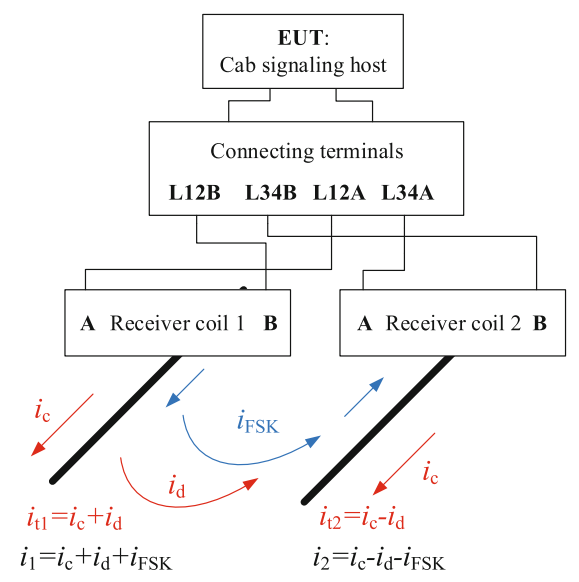

(b) When traction current is unbalanced

Fig. 1 Interference mechanism in the cab signaling system

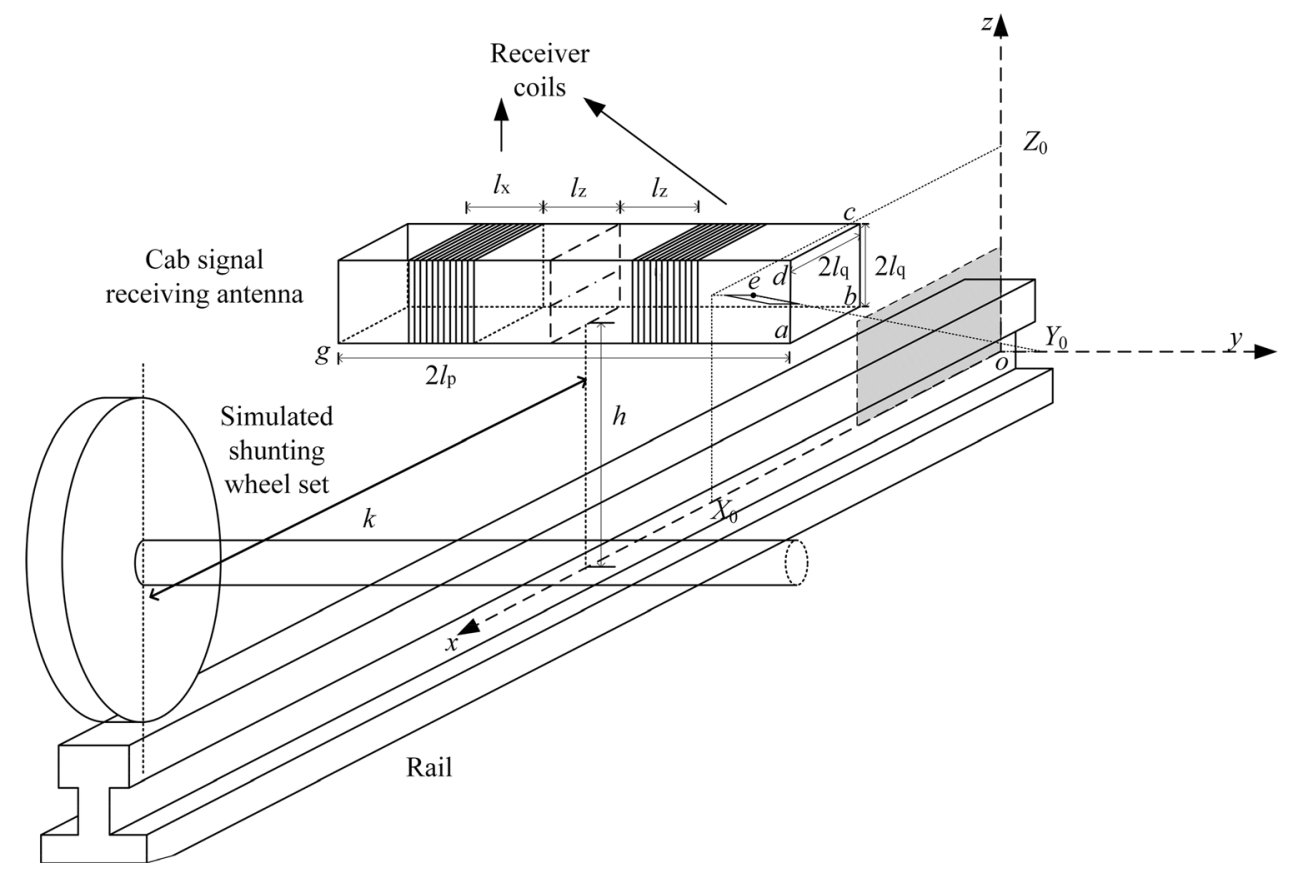

Fig. 2 The rectangular coordinate system

\section{(1) Self-magnetic flux}

Assuming that $e\left(x_{0}, y_{0}, z_{0}\right)$ is any point in space, the rail can be approximated as a long straight conducting wire of length $l=2000 \mathrm{~mm}$ [24]. (Since the frequency of the rail current is low enough in this practical engineering problem, this equivalent treatment is reasonable, and the calculation results will be verified in Sect. 4.1.) According to the BiotSavart law $[25,26]$, in a linear medium, the current in any circuit will generate a magnetic field around the circuit that is proportional to the current in the circuit. Then, the magnetic induction at the point $e$ from the "rail 1 " from coordinate $(0,0,0)$ to $(l, 0,0)$ can be expressed as (3), and the direction of the magnetic induction complies with the right-hand rule.

$$
\begin{aligned}
B_{1}\left(x_{0}, y_{0}, z_{0}, t\right)= & \frac{\mu_{0} \mu_{\mathrm{r}}}{4 \pi} \int_{0}^{l} I_{1}(t) \\
& \times \frac{\sqrt{y_{0}^{2}+z_{0}^{2}}}{\left(\sqrt{\left(\left|x_{0}-x\right|\right)^{2}+y_{0}^{2}+z_{0}^{2}}\right)^{3}} \mathrm{~d} x,
\end{aligned}
$$

where $\mu_{0}$ is the permeability of vacuum $\left(\mu_{0}=4 \pi \times 10^{-7}\right.$ $\mathrm{H} / \mathrm{m}), \mu_{\mathrm{r}}$ is the relative permeability of the transmission 


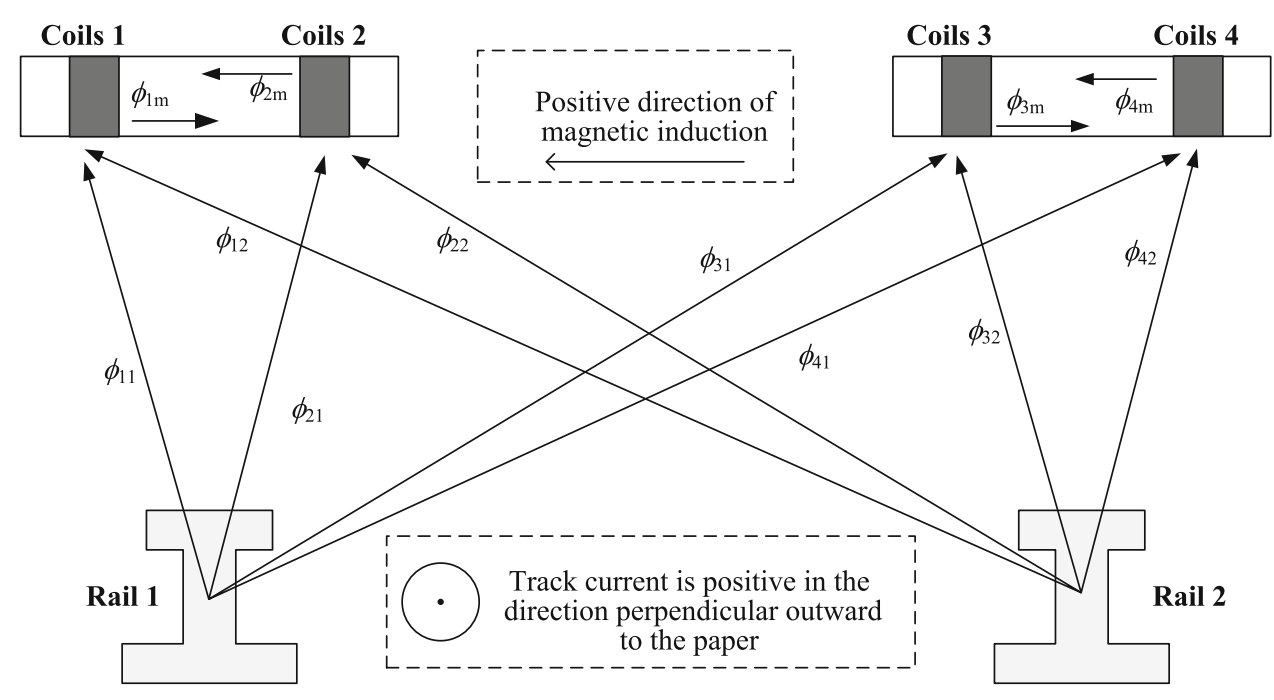

(a) The magnetic flux distribution of the antenna receiver coils

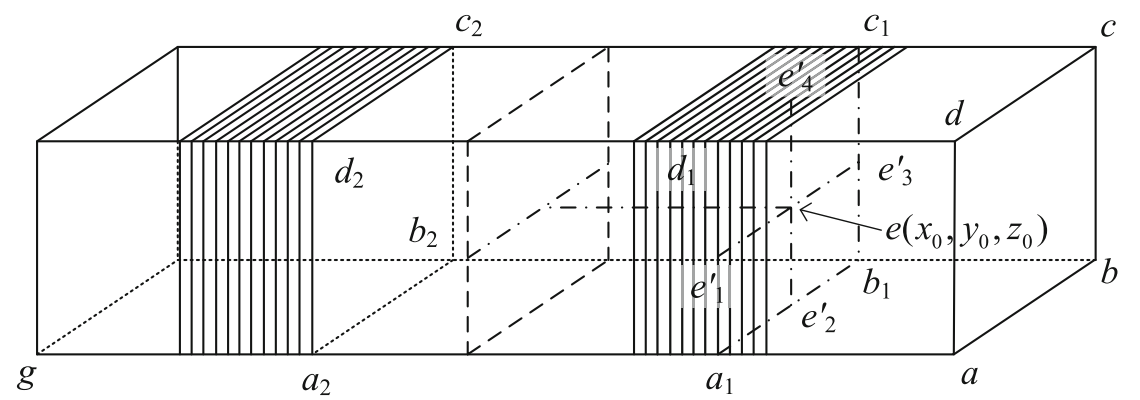

(b) Schematic diagram of mutual inductance calculation

Fig. 3 Schematic diagram of magnetic flux calculation

medium at point $e\left(\mu_{\mathrm{r}}=1.72 \mathrm{~T}\right.$ in this case $)$, and $I_{1}(t)$ is the rail current at any point $(x, 0,0)$ between the rail's transmitting end $(0,0,0)$ and the shunting point $(l, 0,0)$. Similarly, define $y_{0}^{\prime}=y_{0}-d$, the magnetic induction from "rail 2" at point $e$ can be expressed as (4), where $I_{2}(t)$ is the rail current at any point $(x, d, 0)$ between the rail's transmitting end $(0, d, 0)$ and the shunting point $(l, d, 0)$.

$$
\begin{aligned}
B_{2}\left(x_{0}, y_{0}, z_{0}, t\right)= & \frac{\mu_{0} \mu_{\mathrm{r}}}{4 \pi} \int_{0}^{l} I_{2}(t) \\
& \times \frac{\sqrt{y_{0}^{\prime 2}+z_{0}^{2}}}{\left(\sqrt{\left(\left|x_{0}-x\right|\right)^{2}+y_{0}^{\prime 2}+z_{0}^{2}}\right)^{3}} \mathrm{~d} x .
\end{aligned}
$$

Since only the magnetic induction component perpendicular to the cross-section of the coils can cause electromagnetic induction, the effective magnetic induction $B_{1}^{\prime}$ and $B_{2}^{\prime}$ passing through the cross-section of the coils are shown in (5).
$\left\{\begin{array}{l}B_{1}^{\prime}\left(x_{0}, y_{0}, z_{0}, t\right)=B_{1}\left(x_{0}, y_{0}, z_{0}, t\right) \times \cos \theta=B_{1}\left(x_{0}, y_{0}, z_{0}, t\right) \times \frac{z_{0}}{\sqrt{y_{0}^{2}+z_{0}^{2}}} \\ B_{2}^{\prime}\left(x_{0}, y_{0}, z_{0}, t\right)=B_{2}\left(x_{0}, y_{0}, z_{0}, t\right) \times \cos \theta^{\prime}=B_{2}\left(x_{0}, y_{0}, z_{0}, t\right) \times \frac{z_{0}}{\sqrt{y_{0}^{\prime 2}+z_{0}^{2}}}\end{array}\right.$.

According to the coils' specific parameters, the magnetic fluxes $\phi_{B 1}$ and $\phi_{B 2}$ of the unit cross-sectional area from the two rails to the point $e$ in the coils, along the $y$-axis direction, can be expressed as:

$\left\{\begin{array}{l}\phi_{B 1}\left(y_{0}, t\right)=\frac{1}{2 r} \int_{h}^{h+2 l_{q}} \int_{l-k-l_{q}}^{l-k+l_{q}} B_{1}^{\prime}\left(x_{0}, y_{0}, z_{0}, t\right) \mathrm{d} x_{0} \mathrm{~d} z_{0} \\ \phi_{B 2}\left(y_{0}, t\right)=\frac{1}{2 r} \int_{h}^{h+2 l_{q}} \int_{l-k-l_{q}}^{l-k+l_{q}} B_{2}^{\prime}\left(x_{0}, y_{0}, z_{0}, t\right) \mathrm{d} x_{0} \mathrm{~d} z_{0}\end{array}\right.$.

Based on the above, the magnetic fluxes excited by the two rails to the four sets of coils are obtained as follows: 


$$
\left\{\begin{array}{l}
\phi_{11}(t)=\int_{-l_{\mathrm{z}}-l_{\mathrm{x}}}^{-l_{\mathrm{x}}} \phi_{B 1}\left(y_{0}, t\right) \mathrm{d} y_{0} \\
\phi_{21}(t)=\int_{l_{\mathrm{z}}+l_{\mathrm{x}}}^{l_{\mathrm{x}}} \phi_{B 1}\left(y_{0}, t\right) \mathrm{d} y_{0} \\
\phi_{31}(t)=\int_{-l_{\mathrm{z}}-l_{\mathrm{x}}+d}^{-l_{\mathrm{z}}} \phi_{B 1}\left(y_{0}, t\right) \mathrm{d} y_{0} \\
\phi_{41}(t)=\int_{l_{\mathrm{z}}+d}^{l_{\mathrm{z}}+l_{\mathrm{x}}+d} \phi_{B 1}\left(y_{0}, t\right) \mathrm{d} y_{0} \\
\phi_{12}(t)=\int_{-l_{\mathrm{z}}-l_{\mathrm{x}}}^{-l_{\mathrm{z}}} \phi_{B 2}\left(y_{0}, t\right) \mathrm{d} y_{0} \\
\phi_{22}(t)=\int_{l_{\mathrm{z}}+l_{\mathrm{x}}}^{l_{\mathrm{z}}} \phi_{B 2}\left(y_{0}, t\right) \mathrm{d} y_{0} \\
\phi_{32}(t)=\int_{-l_{\mathrm{z}}-l_{\mathrm{x}}+d}^{-l_{\mathrm{z}}} \phi_{B 2}\left(y_{0}, t\right) \mathrm{d} y_{0} \\
\phi_{42}(t)=\int_{l_{\mathrm{z}}+d}^{l_{\mathrm{z}}+l_{\mathrm{x}}+d} \phi_{B 2}\left(y_{0}, t\right) \mathrm{d} y_{0}
\end{array} .\right.
$$

\section{(2) Mutual flux}

There is mutual inductance between two coils on the same magnetic core, and the mutual flux can be expressed as [27]

$\phi_{n \mathrm{~m}}=-M_{\mathrm{c}} \times I_{\mathrm{c}}(t)(n=1,2,3,4)$,

where $I_{\mathrm{c}}$ is the current in the other coils on the same core, and $M_{\mathrm{c}}$ is the mutual inductance coefficient between the coils, which can be calculated according to (9) [28].

$M_{\mathrm{c}}=\int_{h}^{h+2 l_{\mathrm{q}}} \int_{l_{\mathrm{z}}}^{l_{\mathrm{z}}+l_{\mathrm{x}}} \int_{l-k-l_{\mathrm{q}}}^{l-k+l_{\mathrm{q}}} M_{\mathrm{s}} \mathrm{d} x_{0} \mathrm{~d} y_{0} \mathrm{~d} z_{0}$,

where $M_{\mathrm{s}}$ equals the sum of $M_{a b}, M_{b c}, M_{c d}$ and $M_{d a}$, which are the magnetic induction coefficients at the point $e$ from the current in another set of coils on the same core in the directions of $\overrightarrow{a b}, \overrightarrow{b c}, \overrightarrow{c d}$, and $\overrightarrow{d a}$, respectively, as shown in Fig. 3b, and can be figured out by (10).

$$
\left\{\begin{array}{l}
M_{a b}\left(x_{0}, y_{0}, z_{0}\right)=\frac{q_{\mathrm{m}}^{2} \mu_{0} \mu_{\mathrm{r}}}{4 \pi\left(y_{0}-l_{\mathrm{z}}\right)^{2}} \times\left(\frac{e_{1}^{\prime} a_{1}}{e a_{2}}-\frac{e_{1}^{\prime} b_{1}}{e b_{2}}\right) \\
M_{b c}\left(x_{0}, y_{0}, z_{0}\right)=\frac{q_{\mathrm{m}}^{2} \mu_{0} \mu_{\mathrm{r}}}{4 \pi\left(y_{0}-l_{\mathrm{z}}\right)^{2}} \times\left(\frac{e_{2}^{\prime} b_{1}}{e b_{2}}-\frac{e_{2}^{\prime} c_{1}}{e c_{2}}\right) \\
M_{c d}\left(x_{0}, y_{0}, z_{0}\right)=\frac{q_{\mathrm{m}}^{2} \mu_{0} \mu_{\mathrm{r}}}{4 \pi\left(y_{0}-l_{\mathrm{z}}\right)^{2}} \times\left(\frac{e_{3}^{\prime} c_{1}}{e c_{2}}-\frac{e_{3}^{\prime} d_{1}}{e d_{2}}\right) \\
M_{d a}\left(x_{0}, y_{0}, z_{0}\right)=\frac{q_{\mathrm{m}}^{2} \mu_{0} \mu_{\mathrm{r}}}{4 \pi\left(y_{0}-l_{\mathrm{z}}\right)^{2}} \times\left(\frac{e_{4}^{\prime} d_{1}}{e d_{2}}-\frac{e_{4}^{\prime} a_{1}}{e a_{2}}\right)
\end{array}\right.
$$

where $e a_{2}, e b_{2}, e c_{2}$, and $e d_{2}$, respectively, are the distance from the point $e$ to the four vertices of another set of coils, as shown in (11).

$$
\left\{\begin{aligned}
e a_{2} & =\sqrt{\left(l-k+l_{\mathrm{q}}-x_{0}\right)^{2}+\left(h-z_{0}\right)^{2}+\left(-l_{\mathrm{z}}-y_{0}\right)^{2}} \\
e b_{2} & =\sqrt{\left(l-k-l_{\mathrm{q}}-x_{0}\right)^{2}+\left(h-z_{0}\right)^{2}+\left(-l_{\mathrm{z}}-y_{0}\right)^{2}} \\
e c_{2} & =\sqrt{\left(l-k-l_{\mathrm{q}}-x_{0}\right)^{2}+\left(h+2 l_{\mathrm{q}}-z_{0}\right)^{2}+\left(-l_{\mathrm{z}}-y_{0}\right)^{2}} \\
e d_{2} & =\sqrt{\left(l-k+l_{\mathrm{q}}-x_{0}\right)^{2}+\left(h+2 l_{\mathrm{q}}-z_{0}\right)^{2}+\left(-l_{\mathrm{z}}-y_{0}\right)^{2}}
\end{aligned}\right.
$$

In (10), $e_{n}^{\prime} x_{n}(x=a, b, c, d)$ represents the vertical distance from the perpendicular projection on the four planes of the point $e$ to the four edges of the core, which can be calculated according to (12).

$$
\left\{\begin{array}{l}
e_{1}^{\prime} a_{1}=\left|h-z_{0}\right| \\
e_{1}^{\prime} b_{1}=\sqrt{\left(2 l_{\mathrm{q}}\right)^{2}+\left(h-z_{0}\right)^{2}} \\
e_{2}^{\prime} b_{1}=\left|l-k-l_{\mathrm{q}}-x_{0}\right| \\
e_{2}^{\prime} c_{1}=\sqrt{\left(l-k+l_{\mathrm{q}}-x_{0}\right)^{2}+\left(2 l_{\mathrm{q}}\right)^{2}} \\
e_{3}^{\prime} c_{1}=\left|h+2 l_{\mathrm{q}}-z_{0}\right| \\
e_{3}^{\prime} d_{1}=\sqrt{\left(2 l_{\mathrm{q}}\right)^{2}+\left(h+2 l_{\mathrm{q}}-z_{0}\right)^{2}} \\
e_{4}^{\prime} d_{1}=\sqrt{\left(l-k+l_{\mathrm{q}}-x_{0}\right)^{2}+\left(2 l_{\mathrm{q}}\right)^{2}} \\
e_{4}^{\prime} a_{1}=\left|l-k+l_{\mathrm{q}}-x_{0}\right|
\end{array} .\right.
$$

Furthermore, the coils' induced current $I_{\mathrm{c}}$ can be solved by (13) and the function call in MATLAB. Assuming that the input voltage and the equivalent input impedance of the EUT, respectively, are $\varepsilon$ and $Z_{\mathrm{s}}$ (the $\varepsilon$ is a variable depending on the rail current under different time, which will be calculated in Sect. 2.3), since the two sets of coils are equivalent, the equation for $I_{\mathrm{c}}$ is written as

$I_{\mathrm{c}}(t)=\frac{\varepsilon(t)}{Z_{\mathrm{s}}}-I_{\mathrm{c}}(t)$.

\subsection{Derivation of the voltage-current coupling relationship}

Based on the above calculation and analysis of the magnetic flux, the total magnetic flux in the two sets of coils can be expressed as

$$
\left\{\begin{array}{l}
\phi_{L 13}(t)=\phi_{1}(t)+\phi_{3}(t) \\
\phi_{L 24}(t)=\phi_{2}(t)+\phi_{4}(t) .
\end{array}\right.
$$

Due to the redundancy of the receiving antenna, the twin channel fluxes $\phi_{L 13}(t)=\phi_{L 24}(t)$. According to Faraday's law of electromagnetic induction [29], the total electromagnetic force (EMF) of the twin channel receiving antenna can be obtained by (15), and $\varepsilon_{L 13}(t)=\varepsilon_{L 24}(t)$. 
$\left\{\begin{array}{l}\varepsilon_{L 13}(t)=-\frac{\mathrm{d} \phi_{L 13}(t)}{\mathrm{d} t} \\ \varepsilon_{L 24}(t)=-\frac{\mathrm{d} \phi_{L 24}(t)}{\mathrm{d} t}\end{array}\right.$.

It can be found from Sect. 2.1 that the cab signal is transmitted as an FSK signal; i.e., it consists of two sinusoidal signals with different frequencies. In the ZPW2000 track circuit system, the wideband and narrowband near the carrier frequency $f_{\mathrm{c}}$ are, respectively, expressed as $f_{\mathrm{c}} \pm \Delta f_{\mathrm{p}}$, i.e., the mark and space in communication system principle, which together constitute the signal period of $1 / f_{\mathrm{d}}$, and $2 \Delta f_{\mathrm{p}}=\frac{n}{2} R_{\mathrm{b}}$, where $R_{\mathrm{b}}$ is chip rate. To ensure the phase continuity, we adopt the minimum frequency-shift keying (MSK) [30], and its transmission bandwidth can be expressed as

$B_{\mathrm{MSK}}=\frac{1}{2} R_{\mathrm{b}}+2 R_{\mathrm{b}}=2.5 R_{\mathrm{b}}$.

In the cab signals, $\Delta f_{\mathrm{p}}=11 \mathrm{~Hz}$. The frequency offset $\Delta f_{\mathrm{p}}$ is much smaller than the carrier frequency $f_{\mathrm{c}}$, so its characteristics can be approximated by sinusoidal equivalent, and the carrier frequency of the track circuit signal is $1700,2000,2300$, and $2600 \mathrm{~Hz}$, respectively. When the signal carrier angular frequency is recorded as $\omega$, the induced EMF of the receiving antenna can be obtained by

$\left\{\begin{array}{l}\varepsilon_{L 13}(t)=-\phi_{L 13}(t) \times \omega \\ \varepsilon_{L 24}(t)=-\phi_{L 24}(t) \times \omega\end{array}\right.$.

The complete circuit consists of the antenna equivalent induced voltage source, the signaling host (EUT), and two sets of induction coils, as shown in Fig. 4. Among them, let $Z_{\mathrm{c}}$ be the impedance of the single set of coils in the receiving antenna, $\omega$ be the angular frequency of the cab signal or interference, and $Z_{\mathrm{s}}$ be the input impedance of the onboard signaling host. Circuit parameters are specified as follows: $Z_{\mathrm{s}}=4000 \Omega$, the inductance value is $L=63 \mathrm{mH} \pm 3 \mathrm{mH}$, the DC resistance value of the receiver coils is $R \leq 8 \Omega$ generally, and the quality factor is $Q>5.5$ [16]. According to the actual measurement, the
DC resistance of the single set of coils in the receiving antenna is $R \approx 5 \Omega$. On these bases, we can derive

$\left\{\begin{array}{l}Z_{\mathrm{c}}=(5+\mathrm{j} \omega \times 0.63) \Omega \\ Z_{\mathrm{s}}=4000 \Omega\end{array}\right.$.

Therefore, the actual host input voltage of any channel can be figured out by (19). And we define the $C_{\mathrm{v}}$ as the voltage divider coefficient of the host, as shown in (20).

$\varepsilon=\varepsilon_{L 13} \times \frac{Z_{\mathrm{s}}}{Z_{\mathrm{s}}+2 Z_{\mathrm{c}}}=\varepsilon_{L 24} \times \frac{Z_{\mathrm{s}}}{Z_{\mathrm{s}}+2 Z_{\mathrm{c}}}$.

$C_{\mathrm{v}}=\frac{Z_{\mathrm{s}}}{Z_{\mathrm{s}}+2 Z_{\mathrm{c}}}$.

Based on the above analysis, the effective value of the rail signal current is regulated as $500 \mathrm{~mA}$, and the frequency sweep calculation is performed from 0 to $5000 \mathrm{~Hz}$. Finally, we obtain the results of the induced current, the magnetic flux, the coefficient $C_{\mathrm{v}}$, and the EMF within range of $0-5000 \mathrm{~Hz}$ in the cab signaling circuit, as shown in Fig. 5.

In Fig. 5, at first the induced current in coils grows, and then decreases with increasing frequency, and is about 40 to $52 \mathrm{~mA}$ within the signal frequency range of 1700 to $2600 \mathrm{~Hz}$. The self-inductive magnetic flux in the coils does not change with the frequency, whereas the mutual flux rises with the increase of the frequency, leading to a dropdown of the total magnetic flux of the coils as a whole, and the gradient increases first and then decreases. The coefficient $C_{\mathrm{v}}$ is negatively correlated with the frequency; the self-induced EMF and mutual EMF of the coils are both positively correlated with the frequency. The induced EMF of the coils in the receiving antenna also shows an upward trend. The actual input voltage of the host gradually increases with the increase of the frequency, and finally tends to be stable. The signal voltage value coupled to the host in the ZPW-2000 signal carrier frequency range (within the red dashed lines in Fig. 5) is approximately 162 to $207 \mathrm{mV}$, which is approximately linear with the track signal current.

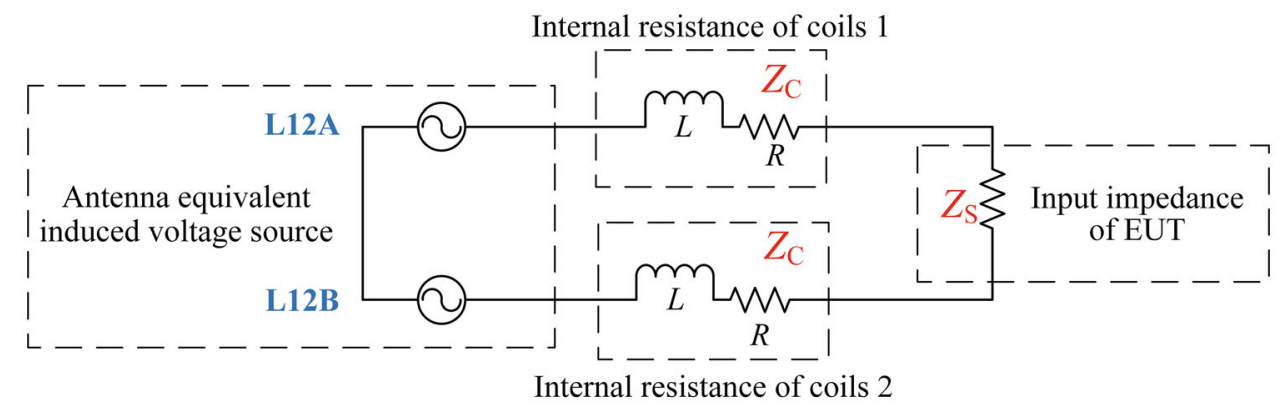

Fig. 4 The actual receiving circuit of the cab signals 


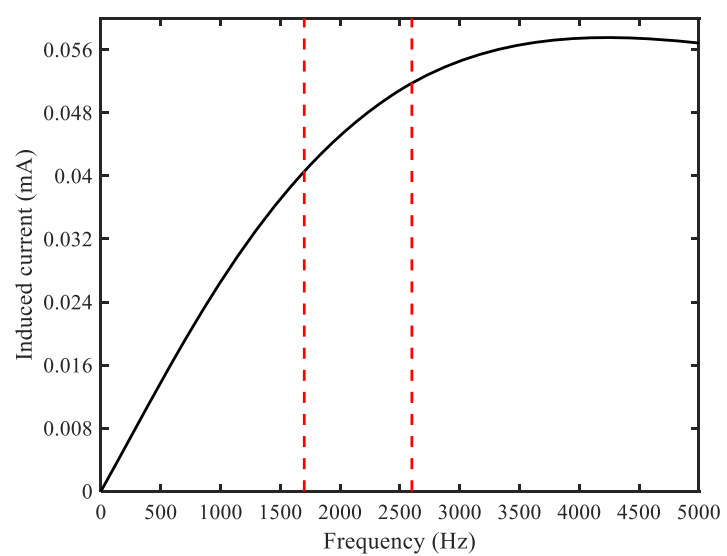

(a) The induced current in coils

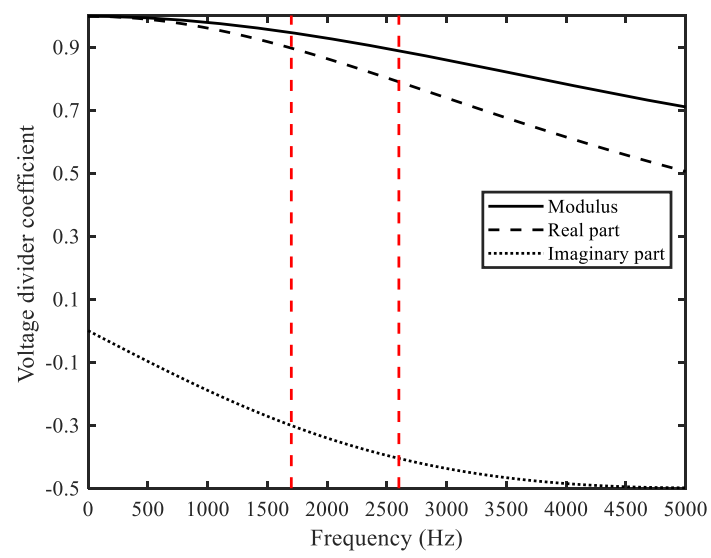

(c) The coefficient $C_{\mathrm{v}}$

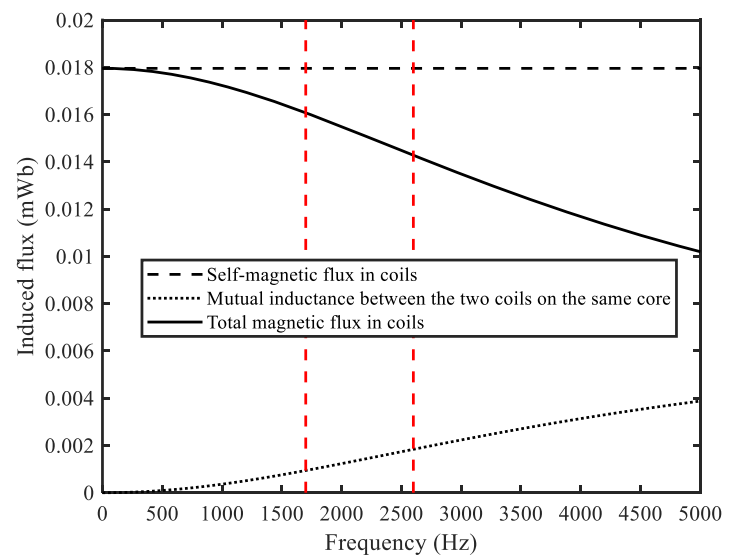

(b) The induced flux in coils

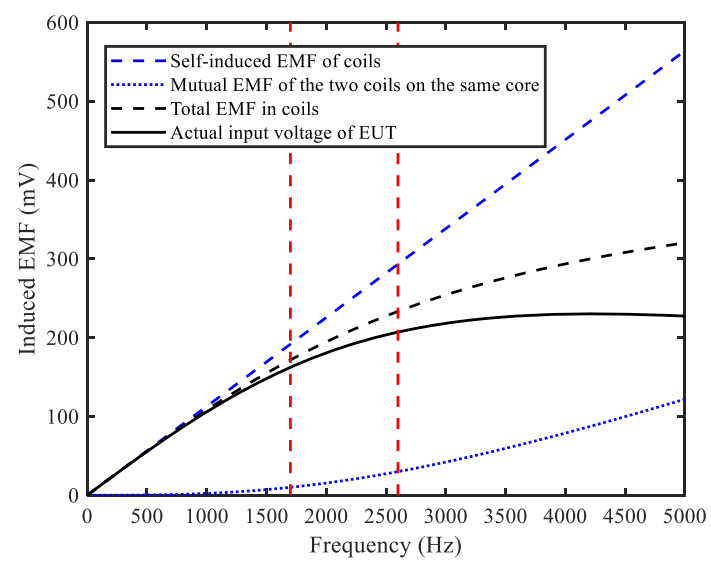

(d) The induced EMF

Fig. 5 Calculation results of the main parameters in the cab signaling system based on the electromagnetic field theory

\subsection{Quantitative calculation of the traction current interference}

The cab signals will be affected by the unbalanced traction current interference, and the calculation conditions refer to Sect. 2.2. We calculate the locomotive input voltage induced from the traction current, which consists of $50 \mathrm{~Hz}$ fundamental wave and 12 harmonic components, according to two test levels in the immunity test. The results are shown in Table 1.

Table 1 shows that the ZPW-2000 is tested for the immunity of the fundamental and harmonics. The input voltage of the corresponding traction current interference component coupled to the host can be calculated according to each current index. In other words, we obtain the accurate coupling relationship between the host's input voltage and rail current in the ground-to-vehicle electromagnetic induction process of the cab signaling apparatus.

\section{Verification of the coupling relationship based on finite element simulation}

The finite element simulation is based on the Ansoft Maxwell platform. According to the actual electromagnetic environment, we complete the cab signaling system simulation by drawing the system model, setting the finite element solution domain, configuring the material library, setting the boundary conditions and the rail current excitation source, and finally dividing the grid [31-33]. The physical parameters of this model are the same as Sect. 2. The simulation shows the magnetic field distribution, as shown in Fig. 6.

The detailed coupling process of the cab signals is demonstrated by adding unbalanced traction current interference to this system. Taking the carrier frequency of $1700 \mathrm{~Hz}$ and the harmonic of $1750 \mathrm{~Hz}$ as an instance, we can obtain the spectrum of the antenna induced signal from the simulation, under the fundamental and harmonic current interference. The results are shown in Fig. 7. 
Table 1 Calculation result of host voltage coupled from fundamental and harmonic current

\begin{tabular}{llll}
\hline Interference type & Frequency & \multicolumn{2}{l}{ Test level 1/test level 2 } \\
\cline { 3 - 4 } & & $\begin{array}{l}\text { Effective value of rail current } \\
(\mathrm{A})\end{array}$ & $\begin{array}{l}\text { Calculation value of host voltage } \\
(\mathrm{mV})\end{array}$ \\
\hline Fundamental interference & 50 & $100.00 / 200.00$ & $827.30 / 1654.60$ \\
Harmonic interference & 1650 & $0.42 / 0.84$ & $66.92 / 133.86$ \\
& 1700 & $0.12 / 0.24$ & $19.52 / 39.06$ \\
1750 & $0.42 / 0.84$ & $69.74 / 139.48$ \\
& 1950 & $0.42 / 0.84$ & $74.86 / 149.72$ \\
& 2000 & $0.12 / 0.24$ & $21.72 / 43.44$ \\
& 2050 & $0.42 / 0.84$ & $77.18 / 154.34$ \\
& 2250 & $0.42 / 0.84$ & $23.32 / 162.64$ \\
& 2300 & $0.12 / 0.24$ & $83.16 / 166.34$ \\
2350 & $0.42 / 0.84$ & $86.42 / 172.84$ \\
2550 & $0.42 / 0.84$ & $24.90 / 49.80$ \\
& 2600 & $0.12 / 0.24$ & $87.84 / 175.7$
\end{tabular}

It can be inferred from Fig. 7 that when the signal current and the unbalanced traction current interference are simultaneously injected in the circuit as two current sources, the voltage component inducted by the receiving antennas at each frequency is essentially the same as the result when the corresponding current source acts alone. Compared with the theoretical calculation results of Sects. 2.3 and 2.4, the cab signals and the traction current interference magnitude result (under the same calculation condition and test level 1) are verified by the finite element simulation, as shown in Table 2.

According to Table 2, the results of the simulation of the track signal current and the interference components coupled into the cab signaling host through the finite element model well match the previous theoretical calculation results, and the odd harmonic is significantly larger than the adjacent even harmonic.

\section{Application in immunity test method}

\subsection{Experimental verification of the coupling relationship}

In order to ensure that the cab signaling apparatus can operate safely and reliably at the electrified railways, it is necessary to conduct a standardized and scientific indoor immunity test before it is put into use. The key point lies in the design of the interference source and coupling circuit. In terms of interference source setting, based on the circuit superposition principle, the common-mode component $i_{\mathrm{c}}$ of the rail current is ignored. Only the differential-mode component $i_{\mathrm{d}}$ is considered, and the fundamental and harmonic frequencies are tested separately. In terms of the coupling circuit designing, the direct method is usually adopted, as shown in Fig. 8a.

In Fig. 8a, a dual-excited signal source circuit consisting of a working signal source and an interference current source injects current into the shunted rails through the coupling/decoupling network simultaneously, which realizes two kinds of signal conductive coupling and mutual isolation between two excitation sources. The impedance of the rails on both sides is unbalanced by setting the simulated rails, so that the interference components can mostly pass through the single-sided rail, causing unbalanced current interference. The currents in the rails on both sides are, respectively, injected into the host through the induction coils forming signal/interference voltage on the receiving antennas. The currents in the two rails are monitored by a current measurement device to achieve the specified indexes (Table 1: Effective value of rail current). By observing whether the cab signaling system can ensure that the signal is correctly displayed and does not degrade within the specified interference current type, amplitude, and duration, the anti-interference performance of the EUT can be judged. In the test, the cab signaling onboard apparatus adopts the same arrangement as the actual configuration, in which the distance between the bottom of the antenna and the rail surface is $155 \mathrm{~mm} \pm 5 \mathrm{~mm}$. After the antenna receives information from the track, it is transmitted to the signal host via the shielded cable, and decoded by the host for the purpose of train control and speed display onboard. For ground equipment, the horizontal distance between the simulated shunting wheelsets and the antennas in the test platform is also $1500 \mathrm{~mm}$. The working signal source is composed of the cab signaling transmitter 


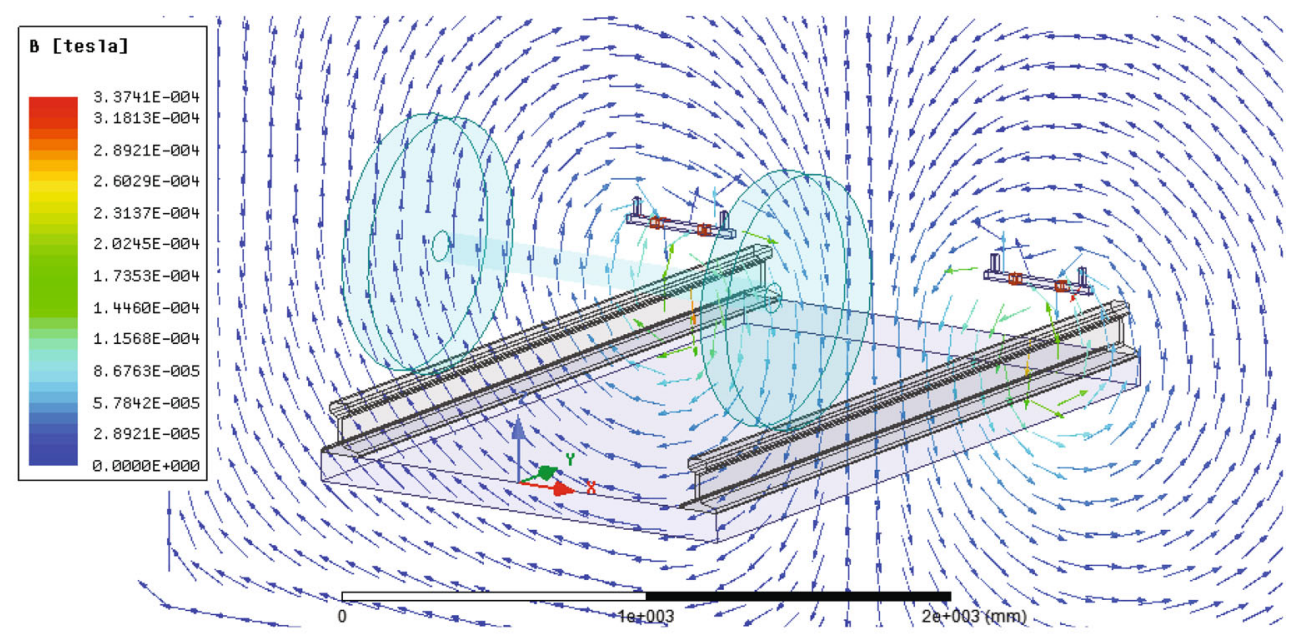

(a) Spatial magnetic field distribution

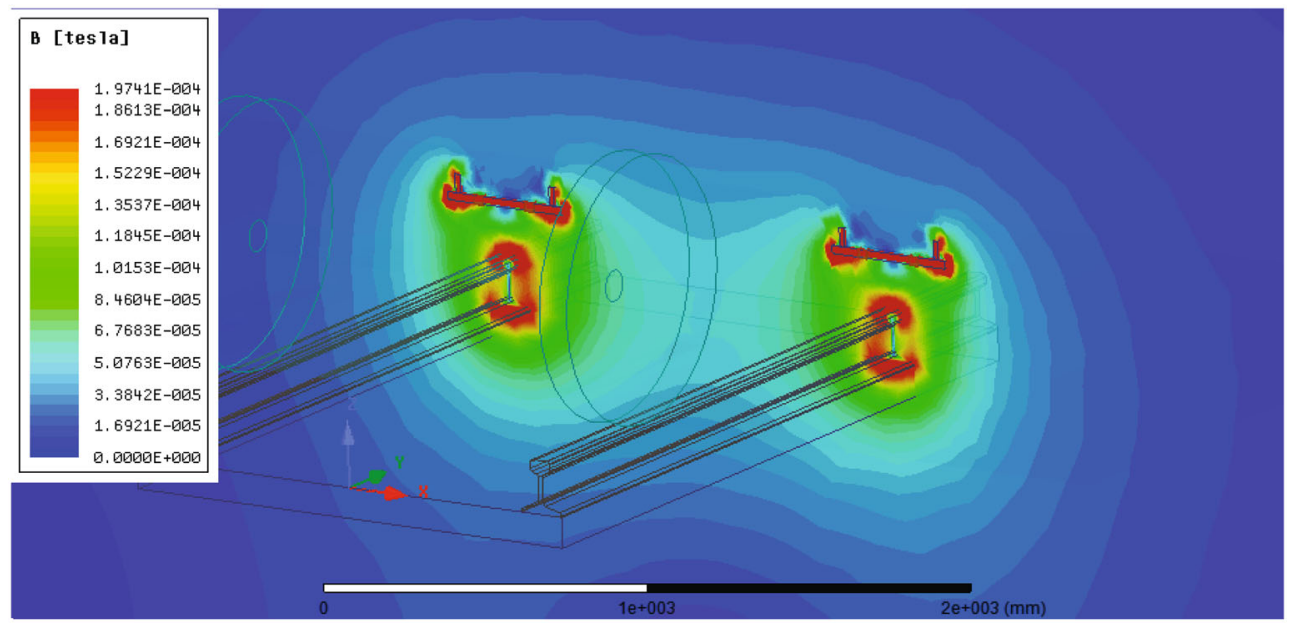

(b) Magnetic field distribution of the vertical section of the antennas

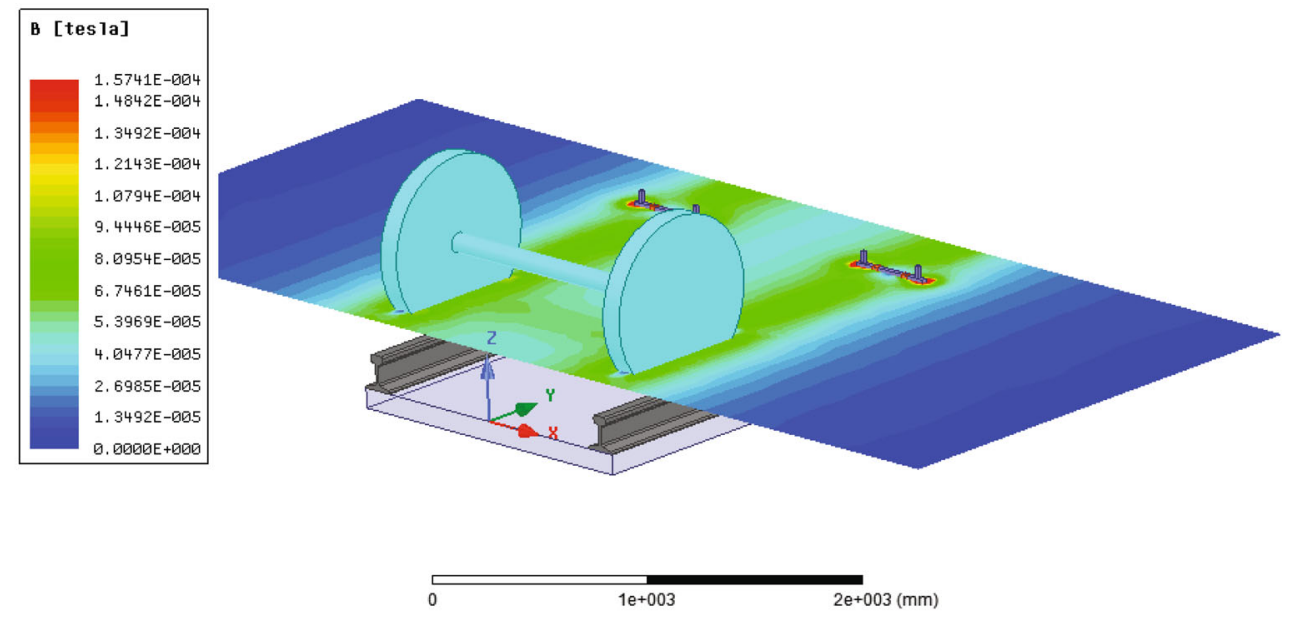

(c) Magnetic field distribution of the horizontal section of the antennas

Fig. 6 The magnetic field distribution of the cab signaling system (traction current frequency: $50 \mathrm{~Hz}$; signal current carrier frequency: $1700 \mathrm{~Hz}$ ) 


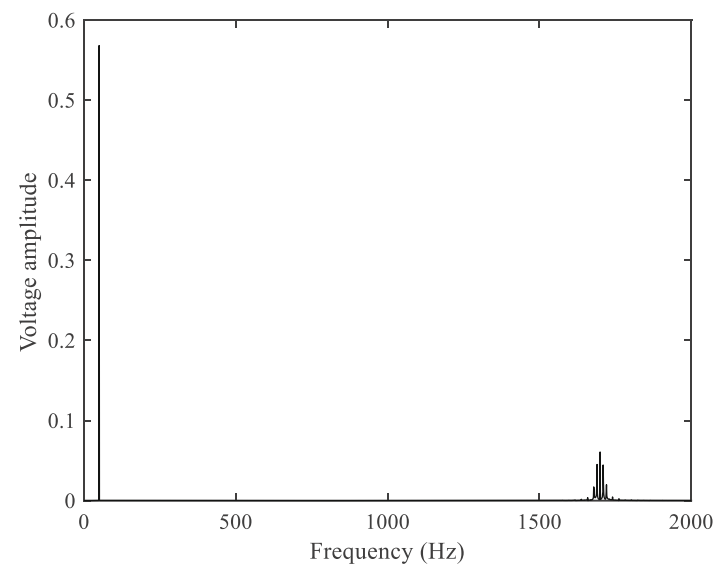

(a) Under fundamental interference

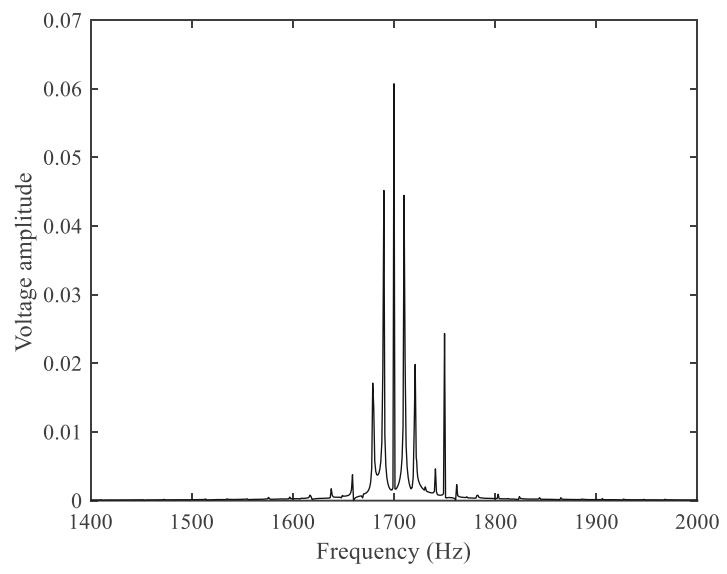

(b) Under harmonic interference

Fig. 7 The spectrum of the antenna EMF

Table 2 Calculation result of host voltage coupled from fundamental and harmonic current

\begin{tabular}{|c|c|c|c|c|c|}
\hline \multirow[t]{2}{*}{ Rail current frequency $(\mathrm{Hz})$} & & \multicolumn{2}{|c|}{ Host input voltage (mV) } & \multirow[t]{2}{*}{ Absolute error $(\mathrm{mV})$} & \multirow[t]{2}{*}{ Relative error $(\%)$} \\
\hline & & Theoretical results & Finite element results & & \\
\hline \multirow[t]{4}{*}{ Carrier frequency } & 1700 & 162.34 & 160.48 & 1.86 & 1.16 \\
\hline & 2000 & 180.60 & 181.73 & 1.13 & 0.62 \\
\hline & 2300 & 195.41 & 195.88 & 0.47 & 0.24 \\
\hline & 2600 & 207.04 & 207.70 & 0.66 & 0.32 \\
\hline Fundamental interference & 50 & 827.30 & 824.06 & 3.24 & 0.39 \\
\hline \multirow[t]{12}{*}{ Harmonic interference } & 1650 & 66.92 & 68.34 & 1.42 & 2.08 \\
\hline & 1700 & 19.52 & 19.58 & 0.06 & 0.31 \\
\hline & 1750 & 69.74 & 71.42 & 1.68 & 2.35 \\
\hline & 1950 & 74.86 & 78.04 & 3.18 & 4.07 \\
\hline & 2000 & 21.72 & 22.58 & 0.86 & 3.81 \\
\hline & 2050 & 77.18 & 81.22 & 4.04 & 4.97 \\
\hline & 2250 & 81.32 & 84.44 & 3.12 & 3.69 \\
\hline & 2300 & 23.50 & 24.04 & 0.54 & 2.25 \\
\hline & 2350 & 83.16 & 87.42 & 4.26 & 4.87 \\
\hline & 2550 & 86.42 & 90.72 & 4.30 & 4.74 \\
\hline & 2600 & 24.90 & 25.58 & 0.68 & 2.66 \\
\hline & 2650 & 87.84 & 92.20 & 4.36 & 4.73 \\
\hline
\end{tabular}

and power amplifier and is injected into the test platform via the artificial network.

After building the actual immunity test platform and testing according to the equivalent configuration of Sect. 2.4, the corresponding relationship between the measurement values and the theoretical calculation values of the system's parameters can be obtained. Firstly, the carrier frequency coupling process is verified. Considering the effect of the frequency offset $\Delta f_{\mathrm{p}}$ in the FSK signal, the $1700 \mathrm{~Hz}$ carrier frequency, whose upper and lower side frequencies, respectively, are 1689 and $1711 \mathrm{~Hz}$, is selected for analysis.
We can refer to Sects. 2.2 and 2.3 to figure out the amplitude ratio of the host's input voltage to the rail current. The corresponding relationship between the calculation result and the measurement data is shown in Fig. 9.

In Fig. 9, the calculated and the measured curve of the amplitude ratio of the input voltage to the rail current are both square waves, the pulse width is $1 / \Delta f_{\mathrm{p}}$, and the amplitude ratio is between 0.323 and 0.327 . Obviously, the mentioned theoretical result is consistent with the measured data, and the result of the calculation of the carrier frequency signal coupling is confirmed. 


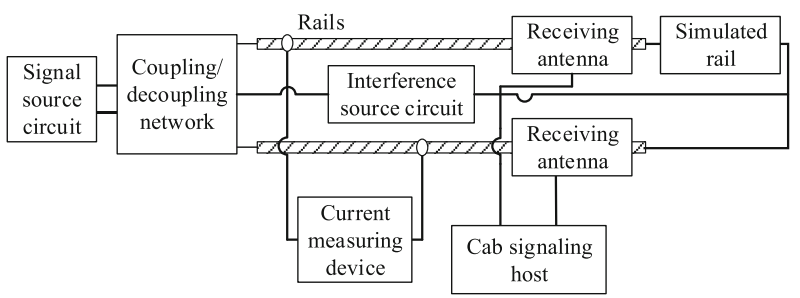

(a) Direct method

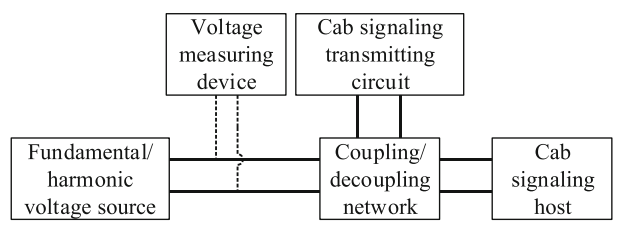

(b) Indirect method

Fig. 8 Immunity test circuit

The overall comparison of the interference coupling is carried out in the fundamental, odd harmonic and even harmonic interfered frequency bands including two steps according to the amplitude:

(1) Considering the fundamental interference currents with effective values of $100 \mathrm{~A}$ and $200 \mathrm{~A}$ (corresponding to two test levels), the measured values of the input voltage of the host are $825.00 \mathrm{mV}$ and $1650.80 \mathrm{mV}$, respectively. Their relative errors with the theoretical calculations are $0.28 \%$ and $0.23 \%$, respectively.

(2) Consider twelve odd and even harmonic interference in total, and the comparison curve between the theoretically calculated value and the measured value is shown in Fig. 10.

Observing the curves in Fig. 10, one can see that the amplitude of the induced EMF received by the host is positively correlated with the frequency of the rail signal, and the gradient of the change is substantially linear, wherein the theoretical value curve is calculated with linearity about $9 \%$, referring to (21), where $\Delta Y_{\max }$ and $Y$, respectively, are the maximum deviation and full-scale output between the theoretical value curve and fitting straight line.

$\delta=\frac{\Delta Y_{\max }}{Y} \times 100 \%$.

As we see, the calculation results (based on the electromagnetic field theory) of the onboard receiving voltage are consistent with the measured results, and the relative errors between the two ranges are from $0.09 \%$ to $2.80 \%$. The above results and analysis convincingly prove that the calculation method of this paper has enough accuracy.

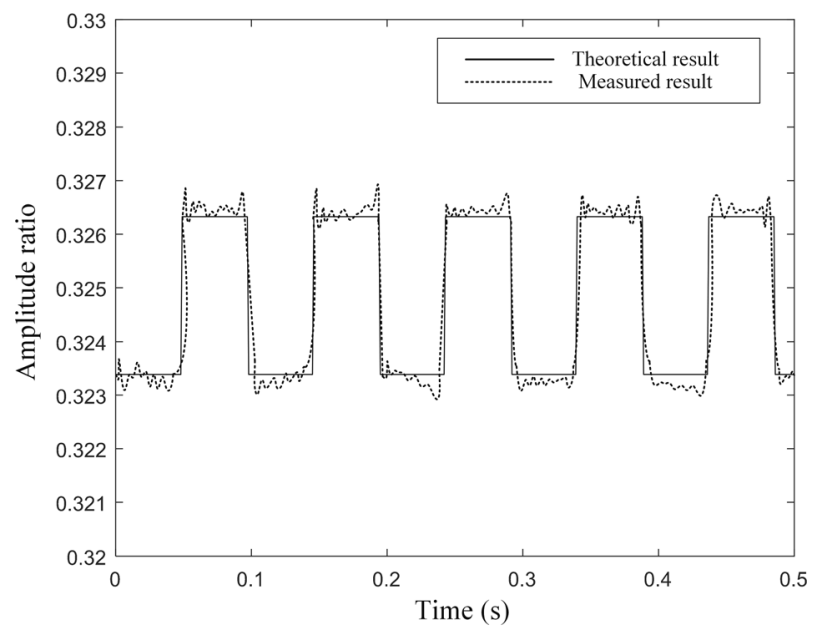

Fig. 9 The amplitude ratio of the input voltage to the rail current

\subsection{Design of the immunity test under indirect method}

From the mentioned actual test, under the direct method, the test circuit is complicated. Also, the operation is cumbersome, and the high current (up to $200 \mathrm{~A}$ in the fundamental wave test) transmitted in the rails may bring some possible safety issues. Therefore, based on the quantitative coupling relationship between the rail current

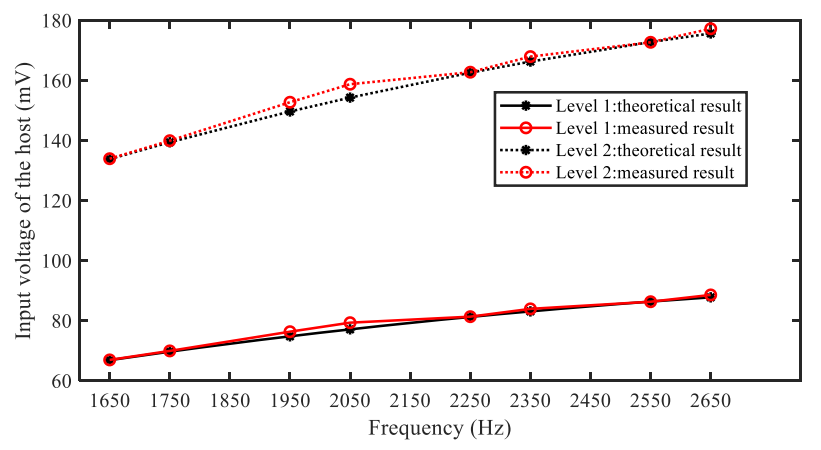

(a) Odd harmonic interference

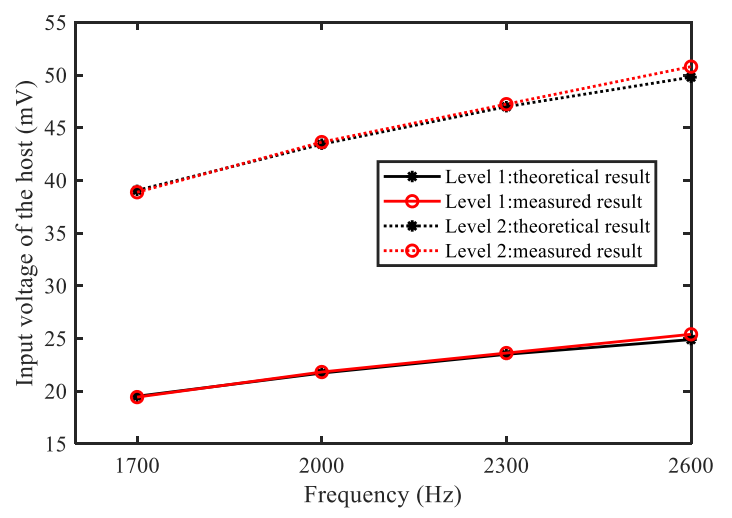

(b) Even harmonic interference

Fig. 10 The verification curves of the interference coupling 
Table 3 Experiment information

\begin{tabular}{|c|c|c|}
\hline Unit & Instruments involved & Main index/accuracy \\
\hline $\begin{array}{l}\text { Fundamental/harmonic } \\
\text { voltage source }\end{array}$ & Signal generator & $\begin{array}{l}\text { The short-circuit output current of the fundamental wave generator: } 200 \mathrm{~A} \pm 2 \mathrm{~A} \text { (RMS }{ }^{\mathrm{a}} \text {; } \\
\text { frequency: } 50 \mathrm{~Hz} \pm 0.5 \mathrm{~Hz} \\
\text { The maximum allowable error of the harmonic frequency: } \pm 0.1 \mathrm{~Hz}\end{array}$ \\
\hline $\begin{array}{l}\text { Voltage measuring } \\
\text { device }\end{array}$ & $\begin{array}{l}\text { Digital recorder (HIOKI } \\
\text { MR8880-21) } \\
\text { Voltage probe }\end{array}$ & $\begin{array}{l}\text { Each channel can select instantaneous value and RMS: } 10 \mathrm{mV}-100 \mathrm{~V} / \mathrm{div}, 13 \text { ranges; } \\
\text { resolution: } 1 / 640 \text { of the range; effective value: } \mathrm{DC}, 30 \mathrm{~Hz}-10 \mathrm{kHz} \text {; crest factor: } 2 \\
\text { 1: } 1 / 1: 10\end{array}$ \\
\hline $\begin{array}{l}\text { Cab signaling } \\
\text { transmitting circuit }\end{array}$ & $\begin{array}{l}\text { General cab signal } \\
\text { transmitter }\end{array}$ & Configured according to specific test requirements \\
\hline $\begin{array}{l}\text { Coupling/decoupling } \\
\text { network }\end{array}$ & Resistance, etc. & Realize signal conductive coupling; isolate signal and interference excitation source \\
\hline Cab signaling host & General cab signaling & Configured according to specific test requirements \\
\hline
\end{tabular}

${ }^{a} R M S$ Root mean square

and the induced voltage, we intend to remove the segment of the interference current conductive coupling through the rails to simplify the test. We adopt the interference voltage at the input end of the cab signaling host, instead of the rail current, as the electromagnetic disturbance source, i.e., the voltage takes the place of the high current, so the immunity test under indirect method is proposed. Its circuit is shown in Fig. $8 \mathrm{~b}$, and the specific experimental information is shown in Table 3.

Different from the direct method, the fundamental and harmonic interference in the test circuit shown in Fig. 8b are injected into the subsequent circuit in the form of voltage. Also, the cab signaling transmitting circuit provides an FSK signal for the vehicle; the voltage measuring device is used to monitor the interference voltage. In Sect. 2.4, we obtain the corresponding host input voltage according to each current index (Table 2: Calculation value of host voltage), which can be used as the system's immunity limit. The accuracy of the voltage indexes has been verified by actual measured data in Sect. 4.1 (Fig. 10).

The indirect test method and voltage injection indexes simplify the immunity test platform and facilitate the immunity test process. Alternatively, they can improve the virtual instrument-based anti-harmonic interference test system of the cab signaling apparatus [34], improving both the test accuracy and efficiency.

\section{Conclusions}

In this paper, for the practical problem that the cab signaling under the ZPW-2000 track circuit is susceptible to electromagnetic interference of traction current components in the rails, a series of studies on interference mechanism analysis, electromagnetic coupling calculation, finite element simulation, and immunity test, were carried out. Conclusions are as follows:

(1) Focusing on quantitative analysis, we realized the coupling calculation of the ground traction current to the cab signaling port in the complete frequency band. Further, we calculated the induced EMF of the host under the unbalanced traction current interference and obtained the voltage-current mapping relation in the conductive and coupling process, which accorded with $9 \%$ linearity in the cab signaling operating frequency range.

(2) We used the finite element method to verify the coupling relationship between the signal or interference current and host voltage. The main sources of interference current include traction current fundamentals and harmonics.

(3) We applied the above quantitative analysis results in the actual test method and immunity test. We finally selected the calculation results of voltage interference limits as the injected indexes to simplify the cab signaling immunity test under the indirect method.

This paper is a further discussion based on EN 50238-2. This work is expected to guide the configuration of voltage indexes in the indirect method test and has application value for equipment development, testing, and maintenance.

Acknowledgements This work was supported in part by the China Railway (Grant No. 17CR062) and Shenzhen Changlong Railway Electronic Engineering Co., Ltd. (Project Name: Anti-interference Design and Verification Improvement of $\mathrm{Cab}$ Signaling Onboard System Apparatus).

Open Access This article is licensed under a Creative Commons Attribution 4.0 International License, which permits use, sharing, adaptation, distribution and reproduction in any medium or format, as long as you give appropriate credit to the original author(s) and the 
source, provide a link to the Creative Commons licence, and indicate if changes were made. The images or other third party material in this article are included in the article's Creative Commons licence, unless indicated otherwise in a credit line to the material. If material is not included in the article's Creative Commons licence and your intended use is not permitted by statutory regulation or exceeds the permitted use, you will need to obtain permission directly from the copyright holder. To view a copy of this licence, visit http://creativecommons. org/licenses/by/4.0/.

\section{References}

1. DD CLC/TS 50238-2: 2010. Railway applications-compatibility between rolling stock and train detection systems-part 2: compatibility with track circuits

2. TB/T 3287-2013. Cab signal systems on board (in Chinese)

3. TB/T 3073-2003. EMC tests and limits for railway electrical signaling apparatus (in Chinese)

4. Augutis V, Gailius D, Misevicius R, Juraska M (2012) Measurements and processing of signals used in a cab signaling system. Elektron Elektrotech 18(9):27-30. https://doi.org/10. 5755/j01.eee.18.9.2800

5. Chen GY, Zhao HB (2010) Virtual instrument based loop inspecting system of cab-signal. In: 2010 International conference on computer design and applications, Qinhuangdao, China. https://doi.org/10.1109/ICCDA.2010.5541486

6. Zhao L, Cai B, Qiu K, Lu Z (2011) The method of diagnosis of compensation capacitor failures with jointless track circuits based on HHT and DBWT. J China Railw Soc 33(3):49-54. https://doi. org/10.3969/j.issn.1001-8360.2011.03.009 (in Chinese)

7. Zhang BW, Xie JJ, Wang ZX, Yang J, Yan H (2018) Research on power-frequency electromagnetic interference model of multicore twisted signal cable of high-speed railway. Turk J Electr Eng Comput Sci 26(4):2077-2087. https://doi.org/10.3906/elk-1712169

8. Charalambous CA, Demetriou A, Lazari AL, Nikolaidis AI (2018) Effects of electromagnetic interference on underground pipelines caused by the operation of high voltage ac traction systems: the impact of harmonics. IEEE Trans Power Deliv 33(6):2664-2672. https://doi.org/10.1109/TPWRD.2018. 2803080

9. Serdiuk T, Feliziani M, Serdiuk K (2018) About electromagnetic compatibility of track circuits with the traction supply system of railway. In: 2018 International symposium on electromagnetic compatibility (EMC EUROPE), Amsterdam, Netherlands. https:// doi.org/10.1109/EMCEurope.2018.8485034

10. Liu WX, Zhang K, Chen XS, Xiong J (2016) Simplified model and submodule capacitor voltage balancing of single-phase $\mathrm{AC} /$ AC modular multilevel converter for railway traction purpose. IET Power Electron 9(5):951-959. https://doi.org/10.1049/ietpel.2015.0120

11. Havryliuk V (2018) Modelling of the return traction current harmonics distribution in rails for ac electric railway system. In: 2018 International symposium on electromagnetic compatibility (EMC EUROPE), Amsterdam, Netherlands. https://doi.org/10. 1109/EMCEurope.2018.8485160

12. Blahnik V, Kosan T, Talla J (2018) Electromagnetic interference of single-phase AC-DC traction converter. In: 2018 18th International conference on mechatronics-mechatronika (ME), Brno, Czech Republic

13. Augutis V, Gailius D, Misevicius R, Pronko V (2010) Analysis of influence of disturbing signals caused by rail magnetization to a cab signaling system. Elektron Elektrotech 101(5):103-106
14. Yang S, Wu Y (2011) Design of conductive interference immunity test for track circuit. J North Jiaotong Univ 25(3):99-102. https://doi.org/10.3969/j.issn.1673-0291.2001.03.026

(in Chinese)

15. Chen Z, Peng L, Qiang X (2004) Research of high sensitivity and high anti-interfering performance locomotive signaling sensor. High Technol Lett 10(6):62-63. https://doi.org/10.3321/j.issn: 1002-0470.2000.06.019 (in Chinese)

16. China Railway Corporation (2016) High-speed railway signaling maintenance regulations (technical specification). China Railway Publishing House, Beijing (in Chinese)

17. Li J, Wu ML, Molinas M, Song KJ, Liu QJ (2019) Assessing high-order harmonic resonance in locomotive-network based on the impedance method. IEEE Access 7:68119-68131. https://doi. org/10.1109/ACCESS.2019.2918232

18. Xiao S, Ma YS, Wen YH, Zhao X (2013) Analysis on the unbalanced loop current of the traction power supply. In: 5th IEEE international symposium on microwave, antenna, propagation and emc technologies for wireless communications (MAPE), Chengdu, China. https://doi.org/10.1109/MAPE.2013. 6689885

19. Yang S, Zhu B, Roberts C, Chen L (2013) Feature-based solution to harmonics interference on track circuit in electrified heavy haul railway. In: 2013 IEEE international conference on intelligent rail transportation proceedings, Beijing, China. https://doi.org/10. 1109/ICIRT.2013.6696311

20. Wang H, Li Y, Liu H, Wu L, Sun Y (2016) Transmission characteristics of harmonics and negative sequence components of electrified railway in power system. In: 6th International conference on smart grid and clean energy technologies (ICSGCE), Chengdu, China. https://doi.org/10.1109/ICSGCE.2016.7876073

21. Tao H, Hu H, Wang X, Blaabjerg F, He Z (2018) Impedancebased harmonic instability assessment in multiple electric trains and traction network interaction system. IEEE Trans Ind Appl 54(5):5083-5096. https://doi.org/10.1109/TIA.2018.2793843

22. Ruehli AE, Antonini G, Jiang L (2017) Circuit oriented electromagnetic modeling using the PEEC techniques. The Institute of Electrical and Electronics Engineers, Inc, Piscataway. https://doi. org/10.1002/9781119078388

23. Ferreira JM, Joaquim A (2018) The magnetic field circulation counterpart to Biot-Savart's law. Eur Phys J Plus 133(6):234. https://doi.org/10.1140/epjp/i2018-12097-7

24. Wu G, Lei D, Dong A, Wang W, Ai B (2009) Distribution property of induced current for rail. J Traffic Transp Eng 9(5):26-31. https://doi.org/10.19818/j.cnki.1671-1637.2009.05. 005 (in Chinese)

25. Soleimani M (2015) Metal flow imaging using a hybrid of electrical capacitance tomography and magnetic induction tomography. In: 3rd International workshop on measuring techniques for liquid metal flows (MTLM 2015), Dresden, UK

26. Rong C, He ZB, Li DW, Yang ZS, Xue GM (2018) Dynamic modeling and analysis of stack giant magnetostrictive actuator. Sens Actuator A-Phys 276(15):205-218. https://doi.org/10.1016/ j.sna.2018.04.020

27. Cabanas MF, Pedrayes F, Melero MG, Rojas CH, Orcajo GA, Cano JM, Norniella JG (2011) Insulation fault diagnosis in high voltage power transformers by means of leakage flux analysis. Prog Electromagn Res 114:211-234. https://doi.org/10.2528/ PIER11010302

28. Ravaud R, Lemarquand G, Lemarquand V, Babic S, Akyel C (2010) Mutual inductance and force exerted between thick coils. Prog Electromagn Res 102:367-380. https://doi.org/10.2528/ PIER10012806

29. Coufal O (2017) Faraday's law of electromagnetic induction in two parallel conductors. Int J Appl Electromagn Mech 54(2):1-18. https://doi.org/10.3233/JAE-160123 
30. Wang Y, Zhang A, Ma J (2017) Research on the system performance evaluation of minimum-shift keying in uplink groundto-satellite with gamma-gamma distribution. Opt Eng 56(7):076113. https://doi.org/10.1117/1.OE.56.7.076113

31. Feliziani M, Maradei F (2000) FEM solution of time-harmonic electromagnetic fields by an equivalent electrical network. IEEE Trans Magn 36(4):918-942. https://doi.org/10.1109/20.877596

32. Zhu T, Liu H, Guan R, Jia S, Yin N (2017) Optimum design method of shunt release based on Ansoft Maxwell. In: 2017 4th International conference on electric power equipment-switching technology (ICEPE-ST), Xi'an, China. https://doi.org/10.1109/ ICEPE-ST.2017.8188953

33. Ma XJ, Tan JY, Liu CG, Wang GD (2015) Simulation of switched reluctance machine with "E" model stator based on Ansoft. In: International conference on automation, mechanical control and computational engineering (AMCCE), Jinan, China

34. Tian J, Wang X, Bo Y (2018) Anti-harmonic interference testing system for cab signal equipment based on virtual instrument. Railw Comput Appl 27(12):51-53, 58. https://doi.org/10.3969/j. issn.1005-8451.2018.12.012 (in Chinese) 